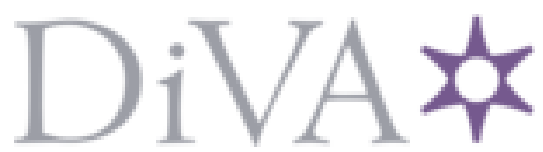

http://www.diva-portal.org

This is the published version of a paper published in .

Citation for the original published paper (version of record):

Bäccman, C., Bergkvist, L., Kristensson, P. (2020)

Elderly and care personnel's user experiences of a robotic shower

Journal of enabling technologies, 14(1): 1-13

https://doi.org/10.1108/JET-07-2019-0033

Access to the published version may require subscription.

N.B. When citing this work, cite the original published paper.

(C) Charlotte Ba"ccman, Linda Bergkvist and Per Kristensson. Published by Emerald Publishing Limited. This article is published under the Creative Commons Attribution (CC BY 4.0) licence. Anyone may reproduce, distribute, translate and create derivative works of this article (for both commercial and non-commercial purposes), subject to full attribution to the original publication and authors. The full terms of this licence may be seen at http:// creativecommons.org/licences/by/4.o/ legalcode

Permanent link to this version:

http://urn.kb.se/resolve?urn=urn:nbn:se:kau:diva-77100 


\title{
Elderly and care personnel's user experiences of a robotic shower
}

\author{
Charlotte Bäccman, Linda Bergkvist and Per Kristensson
}

\begin{abstract}
Purpose - The purpose of this study is to explore the expectations and experiences regarding a robotic shower, from a dual user perspective.

Design/methodology/approach - This was an explorative qualitative study in which elderly and personnel were interviewed before the robotic shower was installed and again after four or five months of usage.

Findings - The elderly participants found the robotic shower empowering. The personnel's experiences encompassed their own work conditions, as well as the user value for the elderly. A shared experience for both user groups was a more independent shower situation for the elderly.

Research limitations/implications - Low user frequency among the elderly may have affected the results; more frequent use may lead to different user experiences. Understanding whether and to what extent long-term use affects user experience is important for future adoption and implementation.

Practical implications - Implementation of digital assistive technology (DAT) should focus on the user value of the DAT for all possible user groups, as the different users may experience different values over time. In addition, approaching adoption and acceptance issues of DAT from a learned helplessness perspective may help users find value in the DAT and the independence these aim to provide, helping users maintain or increase quality of life.

Originality/value - This study presents a dual user experience of a DAT in an intimate care situation and shows the importance of including both elderly and personnel to fully understand the value of DATs.

Keywords Empowerment, Elderly, User experience, Care personnel, Digital assistive technology, Learned helplessness
\end{abstract}

Paper type Research paper

\section{Introduction}

Due to medical progress and improved living conditions, the global population is aging (Coughlin et al., 2006; WHO [World Health Organization], 2018). It has become to readdress the concept of elderly health so that health policies support the ability of older people "to do the things that are important to them regardless of their functional capacity" (Beard and Bloom, 2015, p. 660). Thus, all elderly, regardless of functionality, should have the right to exert control over their own lives and what brings it meaning.

One way to meet some of the challenges of population aging is by means of assistive technology (AT), which aims to facilitate everyday tasks for elderly and persons with chronical illnesses and/or disabilities (Gücin and Berk, 2015; WHO [World Health Organization], 2018). AT can range from a cane to digital assistive technology (DAT) (Flandorfer, 2012; Mytton et al., 2010; Wada et al., 2003; Öberg and Rolfer, 2017); the present study considers the latter category. Apart from facilitating everyday tasks, DATs should support the users' family, friends and care personnel (White and Montgomery, 2014). However, user experiences of DAT in everyday care situations are scarce.
Charlotte Bäccman, Linda Bergkvist and

Per Kristensson are all based at CTF, Service Research Center, Karlstad University, Karlstad, Sweden.
Received 2 July 2019 Revised 9 October 2019 5 December 2019

Accepted 17 December 2019

(C) Charlotte Bäccman, Linda Bergkvist and Per Kristensson. Published by Emerald Publishing Limited. This article is published under the Creative Commons Attribution (CC BY 4.0) licence. Anyone may reproduce, distribute, translate and create derivative works of this article (for both commercial and non-commercial purposes), subject to full attribution to the original publication and authors. The full terms of this licence may be seen at http://creativecommons.org/licences/by/4.0/ legalcode 


\section{Elderly and digital assistive technology}

Most elderly are positive toward technology and strive to maintain independence (Yusif et al., 2016). User experience studies have shown that DAT increases elderly people's empowerment and independence and may allow them to live at home longer (Melander Wikman et al., 2008). Thus, empowering elderly's independence is important, from individual, healthcare and societal perspectives. Autonomy and feeling in control of one's own life are key aspects of quality of life (Bölenius et al., 2019). However, acceptance of DAT depends on user value (Melander Wikman et al., 2008; Tiwari et al., 2010).

One possible negative aspect of DAT is social isolation, which is a significant problem among the elderly, and to some more valuable than independence and integrity (Coughlin et al., 2006; Dorsten et al., 2009). The consequences of social isolation can be as serious as those of smoking, obesity, elevated blood pressure, increased risk for infections and decreased well-being (Dickens et al., 2011; Klinenberg, 2016; Landeiro et al., 2017).

From a healthcare perspective, little is known about how DAT can be implemented in work processes to optimize its value (Coughlin et al., 2006) and its acceptance (Venkatesh and Bala, 2008; Venkatesh and Davis, 2000). Studies imply that organizational resistance to the implementation of new technology (Dorsten et al., 2009) is similar to the resistance of organizational changes in general (Karsh, 2004; Martinko et al., 1996). The causes of such resistance can include the fear of being replaced, as shown among personnel in a study of Tiwari et al. (2010). Hence, user experience, value and acceptance of DAT are areas that remain to be explored (Chau, 1996; Chau and Hu, 2002; Miskelly, 2001; Proffitt et al., 2019; Rho et al., 2014).

With this background, several aspects need to be considered when understanding user acceptance and adoption of DAT. If the purpose of DAT is to improve quality of life, the actual users must be involved in both the implementation and evaluation of the DATs (Kristensson et al., 2015; Öberg and Rolfer, 2017).

This study aimed to explore and understand users' expectations and experiences in a care situation where DAT was applied. In this case, the shower situation. The users in this study were elderly and care personnel (henceforth simply personnel) at an assisted living facility (ALF). The study design was longitudinal with separate purposes at the two different occasions for interviews (see Method, T1 and T2). The results show that these two user perspectives will sometimes concur and sometimes diverge, but both perspectives are equally important to fully understand the value of DATs in care situations.

\section{Method}

The study was conducted over a six-month period at an ALF in a Swedish medium-sized municipality. The ordinary shower routine at the ALF was partially replaced by Poseidon, a late prototype "robotic shower" (Figure 1) designed by Robotics Care (Robotics Care, 2017) to: empower elderly and persons with disabilities in the shower situation, reduce the physical strain on personnel, and prevent slipping accidents. The study was approved by the Ethical Vetting Board in Uppsala (Date of approval: 08-11-2017; registration no. 2017/ 442), with regard to the ethical principles by the World Medical Association (WMA [World Medical Association], 2018), and has thus been deemed to have a design that ensures both the safety of the participants and the trustworthiness of data collection, analysis and reporting.

The robotic shower has a hollow seat (similar to that of a toilet seat) with armrests, attached to an extendable, mechanical arm that brings the person in and out of the shower. This mobile chair increases availability for persons with limited mobility and paralysis. The shower can be adapted to the user's size and preferences; for example, water pressure. 


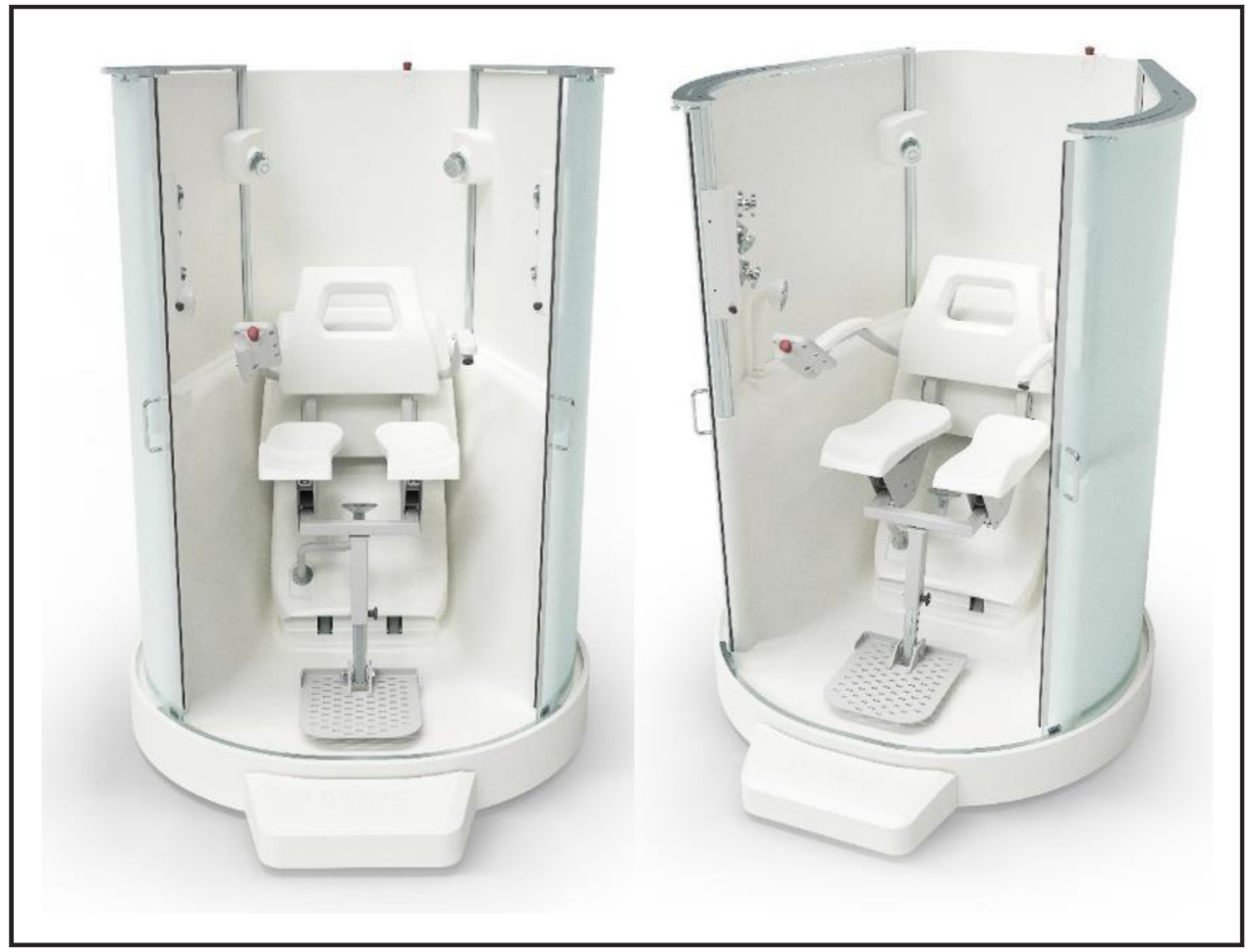

Water and soap are distributed on the upper and lower body by several shower heads. The robotic shower is also equipped with a hand shower and emergency alarm. The shower cabin's sides are frosted for privacy.

\section{Design and procedure}

The study had a dual user perspective, so interviews with both elderly and personnel were conducted before the robotic shower had been installed (T1), and again four to five months after the installment (T2). If possible, and if the inclusion criteria were met, the same participants were interviewed for both $\mathrm{T} 1$ and $\mathrm{T} 2$.

At T1, 11 interviews were conducted: six with elderly and five with personnel. At T2, 10 interviews were conducted: five with elderly and five with personnel. In total, 21 interviews were conducted. All participation was voluntary and all participants gave their informed consent. By the time of $\mathrm{T} 2$ the elderly had tried the robotic shower between one and four times and the interviewed personnel had assisted elderly people in the robotic shower solution between two and 15 times.

The purpose of $\mathrm{T} 1$ was to explore the user experience of the current shower situation and expectations on the robotic shower. The elderly participants were selected by representatives from the municipality. Inclusion criteria were elderly people who:

- normally needed help in the shower situation;

- were healthy enough that they might benefit from a robotic shower; and

- were willing and able to be interviewed.

The participating personnel were all employees at the ALF. 
At T2 the purpose was to assess the user experiences from the robotic shower. The inclusion criterion was that all participants had either used the robotic shower themselves or had assisted someone in doing so.

\section{The participants}

The participants were seven elderly people (E1-7) and seven personnel (P1-7). Five elderly and three personnel were interviewed both at T1 and T2. At T2, two of the elderly were replaced due to worsened health conditions and two of the personnel were replaced because they had not used the robotic shower or no longer worked at the ALF. The ages of the elderly (five men, two women) ranged from 58 to 82 years. The personnel were all women aged 22-59. The age and gender distribution of the participants did not change from $\mathrm{T} 1$ to $\mathrm{T} 2$.

The elderly stayed at the ALF for one to two weeks per month and most had been part-time residents for several years. Reasons for staying varied from cognitive to physical impairments (dementia, limited mobility, etc.). The elderly showered between one to three times a week with support from personnel at home or at the ALF. The degree of required support varied from one elderly person to another: some required help throughout the entire shower situation (undressing, showering and drying), while others managed parts of the shower situation by themselves. The elderly did not consider themselves technically experienced or skilled: some owned a mobile phone but few had used computers.

The personnel had worked at the ALF for at least a couple of years. Many had previous experience from home care and/or healthcare services. The personnel at the ALF practiced a salutogenic work method: a user-centric work method that focuses on the elderly people's abilities rather than their disabilities.

\section{The data analysis}

Data from T1 and T2, and elderly and personnel, were analyzed separately. To ensure the general trustworthiness of the data analysis and the results, the analysis was conducted in accordance with Braun and Clarke's (2006) thematic analysis where the semantic/explicit meaning of the interview is analyzed. All audio-recorded interviews were transcribed by professionals. For the analysis, the researchers used the software application NVivo 12. NVivo helps keep data organized and makes the process of coding and analysis transparent, thus adding to the reliability of the qualitative analysis.

The analysis was iterative but can be described as six steps (Braun and Clarke, 2006). The two first steps were done individually by two of the researchers, to avoid researcher bias. The first step included reading through the interviews carefully to get to know the data from an overall, holistic perspective. The second step was extracting a meaning from each meaning-bearing unit and coding these according to content. In this study, a meaningbearing unit could range from one to several sentences, representing communalities among the units within the code, and the coding was kept close to the data, that is, the coding did not stray far from explicit meaning of the meaning-bearing unit. The second step resulted in initial codes given preliminary names.

This was followed by a joint coding procedure (steps 3-6) to reach consensus. The third step was interpretative with the objective to find protothemes from the initial coding. Here, the initial codes were combined or split according to a common theme and checked again for inconsistencies. In the fourth step, through iterations, the themes were reviewed and reanalyzed according to the emergent protothemes. All themes were examined as to be distinct and separable, that they contained coherent data, and that they represented the entire data set. The fifth step was to further refine and define each theme and give them distinctive and representative labels. This process resulted in themes providing 
understanding of users' expectations on and experiences of the robotic shower. At this point, a unifying understanding of the data emerged from the themes. The sixth and last step was the writing up and reporting of the data and analysis where a model (Figure 2) was created to visualize the data.

\section{Results}

The analysis of elderly and personnel's user experiences from T1 and T2 emerged in 20 themes, presented below.

\section{Elderly participants' experiences of the current shower situation (T1)}

The elderly participants' experiences of the current shower situation, at home and/or at the ALF, emerged in four themes, namely, functionality, control, detachment and gratitude. Functionality expressed positive and negative experiences of effectiveness of the current shower situation, such as how clean they felt, and that one might be pleased, another may long for a thorough soak in the shower. The degree to which the elderly participant felt clean varied depending on the person assisting the shower situation: "/.../[I]t is different depending on whom [gives the shower]: some are very careful whereas others hardly soak me." (E1)

Control regarded the elderly participants' experienced lack of control in the shower situation, such as not having a say in when to shower or for how long. Some of the elderly participants also preferred being showered by same-sex personnel.

Detachment represents experiences of the current shower situation as impersonal and mechanical, where the elderly people's desires and needs are often overridden, as well as stressful and time-limited. Time constraints sometimes caused the personnel to take over tasks that the elderly could master themselves:

I do as much as I can, but sometimes I cannot keep up with the pace. [Home care personnel] are in a bit of a hurry and then rather do [the showering] themselves. (E2)

Gratitude illustrates the elderly's dependence on the personnel and the reluctance to express explicit discontentment with the service provided. Many elderly participants expressed thankfulness for the possibility of being showered at all: "[I]t is very different how

\section{Figure 2 Framework for the dual user perspective of the robotic shower}

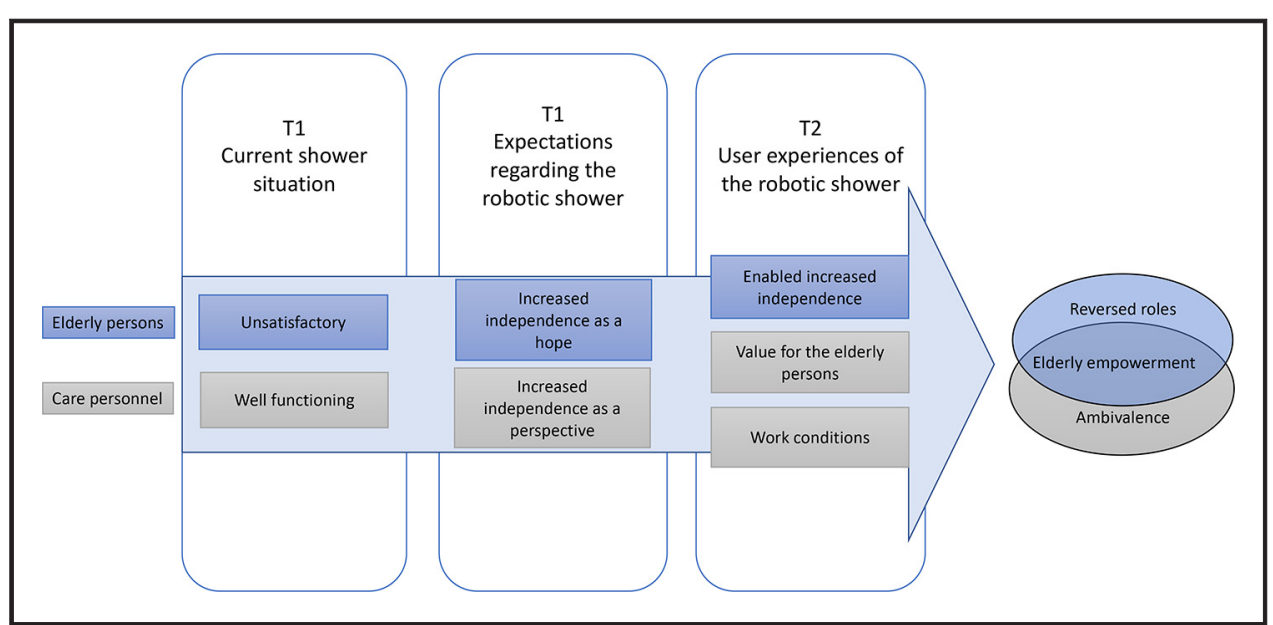


[the personnel] wash my hair. But it is not negative, [the personnel] do the best they can." (E2)

\section{Elderly participants' expectations on the robotic shower (T1)}

The negative experiences of the current shower situation are mirrored in expectations of the robotic shower and the themes: increased independence, partial dependence and insecurity. The first theme regards expectations regarding an increased independent shower situation. Although the elderly realize that they still need help, they hope to manage the actual showering themselves:

I don't have to ask for help/. . ./. I'm not dependent on anyone in the same way if I have a [robotic shower] that fixes everything/.../. [T] hat would be great. (E2)

Partial dependence is the awareness that there are limitations to the independence the robotic shower can provide. The elderly participants acknowledged that they still will need assistance for undressing and dressing and/or getting out from wheelchair to the robotic shower, but most expected to shower by themselves.

Insecurity emerged from concerns about trying the robotic shower: partly regarding the functionality of the robotic shower, partly regarding the novelty of the shower situation. For instance, one interviewee expressed concerns about being "locked up" in the robotic shower and wanted to make sure that personnel were available to monitor the robotic shower.

Overall, the elderly's experiences of the current shower situation are predominantly made up by negative experiences. This is mirrored in their expectations: the elderly were willing to try the robotic shower and hoped that it would allow for a more independent shower situation.

\section{Personnel's experiences of the current shower situation (T1)}

The personnel's experiences of the current shower situation could be understood in three themes, namely, well-functioning, user centric and work conditions. The first theme regards the personnel's routine of giving showers, something that is not considered either bothersome or inconvenient. The shower situation itself is described as being adapted to the needs and wishes of the elderly being showered, and the comfort of the elderly is crucial:

What I find most important is/.../that the [elderly person] is comfortable. Or doesn't feel uncomfortable, because if [he/she] feels uncomfortable I become uncomfortable and then I don't feel that I am being nice. (P3)

The second theme, user centric, comprises of statements regarding how the personnel adjust the shower situation to the elderly. The theme includes how the personnel strive to empower the elderly:

[T]he goal is always that the [elderly person] should be assisted according to their own ability.

That's how we try to work. That someone else doesn't take over. (P1)

Work conditions was partly related to the different tools and work routines that were applied in the shower situation to prevent slipping and heavy lifting; for example, wearing rubber boots to prevent slipping. However, some aspects were unavoidable, such as squatting when washing the lower body, or being kicked by a violent elderly person.

\section{Personnel's expectations on the robotic shower (T1)}

Expectations on the robotic shower regarded hope for an improved shower situation, improved work environment, and concerns about the design of the robotic shower. The first 
theme regarded the personnel's thoughts on how the robotic shower allowed the elderly to become more self-sufficient and comfortable in the shower situation. Improved work environment involved a hope that the robotic shower would relieve some of stress caused by the elderly persons' displeasure with being showered, as exemplified in the quote:

I get really stressed as many [elderly persons] want me to hurry because [they] get cold/. . ./. But here/.../the [elderly] can decide for themselves how long or how hot/.../perhaps it doesn't get cold in [the robotic shower]. (P3)

The last theme, the design, was also related to the elderly's needs, and reflects the personnel's reasoning about who the robotic shower could be helpful for and how the design suited different geriatric symptoms.

With some exceptions, the personnel did not perceive the current shower situation as an issue. However, the personnel recognized that the robotic shower could be valuable for the elderly, perhaps due to their salutogenic work method.

\section{Elderly participants' experiences of the robotic shower (T2)}

The elderly's experiences emerged in the themes of enabled increased independence and continued assistance. The former refers to increased freedom, empowerment, and a more independent shower situation. The robotic shower contributed to a shower situation where elderly could master tasks, as well as decide for how long they wanted to shower:

I can shower when I want, and not when someone comes and will shower me. With [the robotic shower] I can shower independently whether someone helps me or not. (E2)

Although the robotic shower enabled increased independence, the elderly participants still experienced a need for assistance in the shower situation, represented by the theme continued assistance. While the degree of assistance varies with disability, elderly persons generally require assistance to undress, move from wheelchair to the robotic shower, dry off and get dressed. The need for continued assistance can be partly explained by deficiencies in the design of the robotic shower. For example, some elderly experienced problems using the hand shower, and others had difficulty moving from the wheelchair to the robotic shower due the footrest on the mobile chair.

Overall, the elderly had a positive experience of the robotic shower, felt empowered, and looked forward to using it in future. Although they recognized a continued need for support, the experienced benefits were superior.

\section{Personnel's experiences of the robotic shower (T2)}

The personnel's experiences could be categorized into five themes, namely, general attitude, work environment, work processes, unaffected work tasks and value for the elderly. General attitude comprises mainly positive statements regarding how easy the robotic shower was to use, its benefits, and the personnel's willingness to continue using the robotic shower (that is, acceptance). Work environment regards improvements in the shower situation, where some steps have become easier or eliminated by the robotic shower:

It's good, I mean it's never wet when [the elderly person] is to stand up. [W] hen [they] are standing they have already gotten out of the shower, and [the floor] isn't wet for us either. (P3)

This theme also includes statements about how the robotic shower allows for the personnel to increase the elderly persons' independence in the shower situation that is, strengthening their salutogenic work method, sometimes referred to as "working with my hands behind my back". (P7) 
Work processes, were narrations of how the personnel had changed their work routines to be able to use the robotic shower. This included successful adjustments (extra personnel who coordinated the use of the robotic shower), and current work processes that prevented the robotic shower from being used (at times when its use left the floor short-staffed). This theme also includes descriptions of the difficulty of changing routines, such as not just using the ordinary shower.

The theme, unaffected work tasks regards the tasks themselves, regardless of how the work around the tasks are organized. The personnel describes their work tasks as assisting the elderly with everyday tasks of dressing, undressing and assisting them in the other daily activities:

[The elderly person] can of course choose to shower by themselves if they are able. But otherwise it's not very [...] Because you are waiting outside and then you need to help them get dried, apply cream, dress, and so on. (P6)

Value for the elderly involves statements regarding the fit between the elderly and the shower design (such as design issues), a suitable population for the robotic shower, and the personnel's interpretation of how the elderly experienced the robotic shower:

Many [elderly] are weak. Even if they are [mobile], their hands aren't strong enough to [press the button] for as long as it takes the chair to go in and out. (P5)

This theme also contains statements regarding the social interaction. Some of the personnel saw the ordinary shower situation as time for bonding and an opportunity for talking, but this could also apply for the robotic shower:

It is often a bit of fun with the robotic shower. [The elderly person] laughs and find it kind of fun, [the mobile chair] that goes in and out, and the doors that close. And the first couple of times [I

didn't know how to use it]/.../so we had to help each other/.../so I consider [helping and problem solving] a social [bonding] there. (P6)

In sum, the personnel seems to be ambivalent. They were generally positive about the opportunities the robotic shower can offer to some of the elderly, in terms of both increased independence and value. However, the personnel see their own tasks and work conditions as being rather unaffected; they still assist, to varying degrees, in the shower situation. Likewise, while the personnel were reluctant to embrace some the organizational changes that the robotic shower brought (all of which were not possible to resolve), they recognized benefits for their own work conditions in the shower situation. Thus, the robotic shower brought both challenges and benefits.

\section{Conceptualization}

The result from the data analysis shows that these two user perspectives will sometimes concur and sometimes diverge. However, both users' perspectives are equally important to fully understand the value of implementing DATs. A proposed conceptualization of the dual user perspective is outlined in Figure 2.

The elderly user's expectations on and experiences of the robotic shower is illustrated in the first row of Figure 2. The elderly generally found their current shower situation unsatisfactory and hoped that the robotic shower would grant them more independence. Their hope for increased independence was generally realized by the robotic shower. Thus, the elderly participants' shower situation seems to have been overturned from an unsatisfactorily passive role of being showered to a more independent role in the shower situation.

The second row in the conceptualization represents the personnel's twofold perspective as users on the robotic shower, where their professional role allowed them to take on both their own personal perspective and that of the elderly. The personnel described the current 
shower situation as well-functioning, and while they had very little expectations on the robotic shower for themselves; the robotic shower was expected to increase the elderly user's independence. The personnel's user experiences can be described as ambivalent, where they experienced increased value in some conditions, particularly for the elderly users, whereas their own work conditions remained the same (they would still assist in the shower) or even worsened (difficulties of finding new work routines). Thus, the personnel's user experiences were comprehensive and ambivalent, where their professional roles allowed for a broader user perspective. While the personnel and the elderly participants conceded that part of the shower situation would remain unchanged, the overall effect experienced by all users was one of empowerment.

\section{Discussion}

The aim of this study was to explore the expectations on and experiences from a DAT - in this case, a robotic shower - from a dual user perspective: elderly and personnel. The study shows the importance of examining the user experience and user value from various user perspectives (Chau, 1996; Chau and Hu, 2002; Miskelly, 2001; Proffitt et al., 2019; Rho et al., 2014). As our results show, both the elderly and the personnel found the shower solution valuable, which is an important aspect for technology acceptance (Melander Wikman et al., 2008; Venkatesh and Bala, 2008; Venkatesh and Davis, 2000). Overall, the elderly participants expressed a more positive experience than the personnel in terms of increased independence and empowerment. Although the personnel expressed and described more inhibiting factors for adoption, related to work conditions (Coughlin et al., 2006; Rho et al., 2014), they still recognized the benefits and value that the DAT solution had for the elderly users. The personnel also found unexpected values of the robotic shower, such as not having to wipe the wet floor after the shower. Perhaps more importantly, the personnel learned that their roles would remain much the same regardless of how the elderly showered, meaning they would still be needed. DATs cannot replace their roles - a fear that, as Tiwari et al. (2010) showed, may be symptomized as resistance toward DAT among personnel.

A general concern of replacing personal care with DATs is the loss of social interaction (Coughlin et al., 2006; Dorsten et al., 2009), as social isolation is a widespread problem among elderly (Klinenberg, 2016). However, loss of social interactions was not an issue for the elderly participants in the present study. One reason may be the shower situation itself, where showering is such an intimate situation that other types of care situations are incomparable. This creates higher user value for the robotic shower in comparison to, for example, surveillance technology (Melander Wikman et al., 2008). From an ethical perspective, it is important to keep the issue of social isolation in mind before implementing DATs, regardless of situation intimacy, as the the consequences of social isolation can be severe (Dickens et al., 2011; Klinenberg, 2016; Landeiro et al., 2017). Therefore, user acceptance (Venkatesh and Bala, 2008; Venkatesh and Davis, 2000) should be understood in regard to both the specific care situation, and the user value (Melander Wikman et al., 2008).

The user value of the robotic shower seems to have lasted over time. Several months after the study ended, elderly users made the effort to go, on their own, from their permanent homes to use the robotic shower at the ALF rather than shower in their homes with help from home care personnel. This suggests that the effect of empowerment in one situation may cause ripple effects that encourage the elderly to continue to strive for independence and prevent the occurrence of learned helplessness. Learned helplessness (Faulkner, 2001; Flannery, 2002; Hiroto and Seligman, 1975, Seligman, 2011) is a psychological state that follows when a person experiences that a certain situation is beyond his/her control.

Faulkner (2001) showed that learned helplessness spreads from one situation to another, causing elderly people to become care-dependent even in situations unrelated to the 
original situation and skill set. This feeling of powerlessness may affect overall wellbeing (Flannery, 2002; Seligman, 2011). However, healthcare may not necessarily recognize or address this common phenomenon, and will instead discuss it in terms of a lack of motivation. For example, Agree and Freedman (2003) showed that elderly with ATs, regardless of disability and severity, less often considered themselves in need of hands-on care. Lilja et al. (2003) found that elderly's attitudes toward rehabilitation differed, regardless of their need for rehabilitation. The elderly who accepted rehabilitation were those with most ATs and home modifications and tended to strive for independence, whereas those who declined rehabilitation had less ATs and less home modifications and required more frequent help from different home care provisions. This latter group was more dependent on outside care and felt that the time for rehabilitation had passed. Thus, different attitudes could be explained by learned helplessness, which also could explain the low motivation and attitudes toward change (Faulkner, 2001; Seligman, 2011). Recognizing that motivational differences can be an effect of learned helplessness (which is a situational effect), instead of seeing them as individual characteristics, may change how low motivation and change resistance are resolved.

\section{Conclusions}

The conclusion from our study is that new technologies, such as DATs, have the potential to affect several types of users, in our case elderly and personnel, both immediately but also, importantly, in the long term. Taken together, our study stresses the importance of patience, as some of the DAT's benefits only appeared after a while.

Another important conclusion from this study regards the importance of having a dual user perspective to understand how DATs are experienced within healthcare, as elderly and personnel's user experiences will sometimes concur and sometimes diverge. This notion is made as most studies only focus on one user group and thereby risk not getting the integrated picture that new technology will bring about. Furthermore, the study further found that enablers and/or inhibitors for value-creation differed between elderly and personnel, which is why it is important to consider both user perspectives when new DATs are tested or implemented (Melander Wikman et al., 2008; Vargo and Lusch, 2004).

The dual user perspective also gave an important shift in experience for both the elderly and the personnel. The robotic shower enhanced that the personnel were there to help them shower, not to give them a shower. Although the shower situation largely remained the same the elderly still needed assistance getting undressed and dressed, dried, and so on - the elderly users were reminded of their right to independence. Similarly, the personnel were reminded of their work policy to only assist the elderly when needed, not do the work for them. Thus, this study highlights the importance of creating care routines that do not deprive the elderly of their independence and sense of control. An important conclusion is the recognition of how little needs to be changed for increased empowerment of the elderly, and that these small changes can have significant effects on the overall attitudes toward care situations.

\section{Limitations and future research}

One limitation of this study was the fact that the robotic shower was a prototype with possible substandard performance issues that may have affected user experience and perceived value. However, the fact that the robotic shower is still in full use may indicate that this limitation was minor.

As with qualitative studies, the trustworthiness of the data and its interpretation can always be discussed. With regard to the interpretation, despite keeping the analysis close to the empirical data, using the iterative process recommended by Braun and Clarke (2006), and continuous discussions about the results with key persons at the municipality, there is always risk of possible alternative interpretations of data. When it comes to the 
trustworthiness of the data, we suspect that the elderly participants took care not to be too negative about the personnel, whom they are clearly dependent on, for fear of this getting back to the personnel. Similarly, the personnel might have feared that being overly negative about the ALF, its supervisors or residents would have repercussions for their employment even though it was made clear that this was not a risk for the participating personnel. However, this is not likely to have affected the results since the present study aimed to explore the user experience of the DAT.

A potential threat to the reliability of this study is the reliance on qualitative data from a sample with low user frequency. Therefore, future studies should attempt to observe the effects of a more frequent use, allowing the users to learn more about the robotic shower's weaknesses and strengths. In addition, as the municipality have found positive ripple effects on other behaviors, future studies should also expand their focus to include how the use of DATs can affect other types of behaviors. In particular, future research should include the important temporal effects (immediate value-creation and long-term) described in this research.

\section{Practical implications}

This study recommends that all implementation of DAT should focus on the user value of the DAT for all possible user groups, as the different users may experience different values over time. Moreover, all care routines should be designed to support the independence of elderly people; to prevent learned helplessness (Faulkner, 2001; Seligman, 2011), allowing the elderly users to maintain or increase independence and quality of life (Beard and Bloom, 2015; Bölenius et al., 2019).

From a societal point of view, strengthening elderly's self-efficacy can help them remain independent and stay in their homes longer, as well as allow the personnel to provide care and support where it is most needed.

\section{References}

Agree, E.M. and Freedman, V.A. (2003), "A comparison of assistive technology and personal care in alleviating disability and unmet need", The Gerontologist, Vol. 43 No. 3, pp. 335-344.

Beard, J. and Bloom, D. (2015), "Towards a comprehensive public health response to population ageing", The Lancet, Vol. 385 No. 9968, pp. 658-661.

Bölenius, K., Lämås, K., Sandman, P.-O., Lindkvist, M. and Edvardsson, D. (2019), "Perceptions of selfdetermination and quality of life among Swedish home care recipients - across-sectional study", BMC Geriatrics, Vol. 19 No. 1, pp. 142-150.

Braun, V. and Clarke, V. (2006), "Using thematic analysis in psychology", Qualitative Research in Psychology, Vol. 3 No. 2, pp. 77-101.

Chau, P.Y.K. (1996), "An empirical assessment of a modified technology acceptance model”, Journal of Management Information Systems, Vol. 13 No. 2, pp. 185-204.

Chau, P.Y.K. and Hu, P.J.-H. (2002), "Investigating healthcare professionals' decisions to accept telemedicine technology: an empirical test of competing theories", Information \& Management, Vol. 39 No. 4, pp. 297-311.

Coughlin, J.F., Pope, J.E., Ben, R. and Leedle, J. (2006), "Old age, new technology, and future innovations in disease management and home health care", Home Health Care Management \& Practice, Vol. 18 No. 3, pp. 196-207.

Dickens, A.P., Richards, S.H., Greaves, C.J. and Campbell, J.L. (2011), "Interventions targeting social isolation in older people: a systematic review", BMC Public Health, Vol. 11 No. 1, pp. 647-669.

Dorsten, A.M., Sifford, S.K., Bharucha, A., Person Mecca, L. and Wactlar, H. (2009), "Ethical perspectives on emerging assistive technologies: insights from focus groups with stakeholders in longterm care facilities", Journal of Empirical Research on Human Research Ethics, Vol. 4 No. 1, pp. 25-36. 
Faulkner, M. (2001), "The onset and alleviation of learned helplessness in older hospitalized people", Aging \& Mental Health, Vol. 5 No. 4, pp. 379-386.

Flandorfer, P. (2012), "Population ageing and socially assistive robots for elderly: the importance of sociodemographic factors for user acceptance", International Journal of Population Research, Vol. 2012, pp. 13.

Flannery, R.B. Jr. (2002), "Treating learned helplessness in the elderly dementia patient: preliminary inquiry", American Journal of Alzheimer's Disease \& Other Dementiasr, Vol. 17 No. 6, pp. 345-349.

Gücin, N.Ö. and Berk, Ö.S. (2015), "Technology acceptance in health care: an integrative review of predictive factors and intervention programs", Procedia - Social and Behavioral Sciences, Vol. 195, pp. 1698-1704.

Hiroto, D. and Seligman, M.E.P. (1975), "Generality of learned helplessness in man", Journal of Personality and Social Psychology, Vol. 31 No. 2, pp. 311-327.

Karsh, B. (2004), "Beyond usability: designing effective technology implementation systems to promote patient safety", Quality and Safety in Health Care, Vol. 13, pp. 388-394.

Klinenberg, E. (2016), "Social isolation, loneliness, and living alone: identifying the risks for public health", American Journal of Public Health, Vol. 106 No. 5, pp. 786-787.

Kristensson, P., Brunstrom, A. and Pedersen, T. (2015), "Affective forecasting of value creation: professional nurses' ability to predict and remember the experienced value of a telemedicine diagnostics ICT service", Behaviour \& Information Technology, Vol. 34 No. 10, pp. 964-975.

Landeiro, F., Barrows, P., Musson, E.N., Gray, A.M. and Leal, J. (2017), "Reducing social isolation and Ioneliness in older people: a systematic review protocol”, BMJ Open, Vol. 7 No. 5, pp. e013778.

Lilja, M., Bergh, A., Johansson, L. and Nygård, L. (2003), "Attitudes towards rehabilitation needs and support from assistive technology and the social environment among elderly people with disability", Occupational Therapy International, Vol. 10 No. 1, pp. 75-93.

Martinko, M.J., Zmud, R.W. and Henry, J.W. (1996), "An attributional explanation of individual resistance to the introduction of information technologies in the workplace", Behaviour \& Information Technology, Vol. 15 No. 5, pp. 313-330.

Melander Wikman, A., Fältholm, Y. and Gard, G. (2008), “Safety vs. privacy: elderly persons' experiences of a mobile safety alarm”, Health \& Social Care in the Community, Vol. 16 No. 4, pp. 337-346.

Miskelly, G. (2001), "Assistive technology in elderly care”, Age and Ageing, Vol. 30 No. 6, pp. 455-458.

Mytton, O.T., Velazquez, A., Banken, R., Mathew, J.L., Ikonen, T.S., Taylor, K. and Ruelas, E. (2010), "Introducing new technology safely", Quality and Safety in Health Care, Vol. 19 No. 2, pp. i9-i14.

Öberg, A.D. and Rolfer, B. (2017), "Välfärdsteknologi handlar inte om teknik utan om människor tekniksprång i nordisk demensvård. Nordens välfärdscenter", (in Swedish), available at: http:// nordicwelfare.org/PageFiles/41831/Demens-inspirationsha\%cc\%88fte-webb.pdf (accessed 14 March 2019).

Proffitt, R., Glegg, S., Levac, D. and Lange, B. (2019), "End-user involvement in rehabilitation virtual reality implementation research", Journal of Enabling Technologies, Vol. 13 No. 2, pp. 92-100.

Rho, M.J., Choir, I.Y. and Lee, J. (2014), "Predictive factors of telemedicine service acceptance and behavioral intention of physicians", International Journal of Medical Informatics, Vol. 83 No. 8 , pp. 559-571.

Robotics Care (2017), "Poseidon - den intelligenta duschlösningen", (in Swedish), available at: www. roboticscare.com/poseidon/ (accessed 12 February 2019).

Seligman, M.E.P. (2011), Learned Optimism. How to Change Your Mind and Your Life, Simon \& Schuster, Riverside, US.

Tiwari, P., Warren, J. and Day, K.J. (2010), "Some non-technology implications for wider application of robots assisting older people", Health Care and Informatics Review Online, Vol. 14 No. 1, pp. 2-11.

Vargo, S.L. and Lusch, R.F. (2004), "Evolving to a new dominant logic for marketing", Journal of Marketing, Vol. 68 No. 1, pp. 1-17.

Venkatesh, V. and Bala, H. (2008), "Technology acceptance model 3 and a research agenda on interventions", Decision Sciences, Vol. 39 No. 2, pp. 273-315. 
Venkatesh, V. and Davis, F.D. (2000), "A theoretical extension of the technology acceptance model: four longitudinal field studies", Management Science, Vol. 46 No. 2, pp. 186-204.

Wada, K., Shibata, T., Saito, T. and Tanie, K. (2003), "Effects of robot assisted activity to elderly people who stay at a health service facility for the aged", Proceedings 2003 IEEE/RSJ International Conference on Intelligent Robots and Systems (IROS 2003) in Las Vegas, NV, USA, IEEE, Piscataway, NJ, Vol. 3 , pp. 2847-2852.

White, E.B. and Montgomery, P. (2014), "Electronic tracking for people with dementia: an exploratory study of the ethical issues experienced by carers in making decisions about usage", Dementia, Vol. 13 No. 2, pp. 216-232.

WHO (World Health Organization) (2018), "Ageing and health", available at: www.who.int/news-room/ fact-sheets/detail/ageing-and-health (accessed 12 February 2019).

WMA (World Medical Association) (2018), "Declaration of Helsinki. Ethical principles for medical research involving human subjects", WMA General Assembly, Fortaleza, Brazil, October 2013, available at: www.wma.net/wp-content/uploads/2018/07/DoH-Oct2008.pdf (accessed 8 November 2019).

Yusif, S., Soar, J. and Hafeez-Baig, A. (2016), "Older people, assistive technologies, and the barriers to adoption: a systematic review", International Journal of Medical Informatics, Vol. 94, pp. 112-116.

\section{Corresponding author}

Charlotte Bäccman can be contacted at: charlotte.baccman@kau.se

For instructions on how to order reprints of this article, please visit our website: www.emeraldgrouppublishing.com/licensing/reprints.htm

Or contact us for further details: permissions@emeraldinsight.com 